\title{
Exigência de lisina digestível de frangos de corte machos de 22 a 42 dias de idade
}

\author{
[Digestible lysine levels of male broilers from 22 to 42 days of age] \\ V.C. Caetano ${ }^{1}$, L.F. Demuner ${ }^{1}$, D. Suckeveris ${ }^{2}$, J.A. Muñoz ${ }^{1}$, \\ D.E. Faria Filho ${ }^{1}$, D.E. Faria ${ }^{1}$
}

${ }^{1}$ Universidade de São Paulo - Faculdade de Zootecnia e Engenharia de Alimentos - Pirassununga, SP
${ }^{2}$ Universidade de São Paulo - Escola Superior de Agricultura Luiz de Queiroz - Piracicaba, SP

\section{RESUMO}

O objetivo deste estudo foi determinar a exigência de lisina digestível para frangos de corte machos sob as características de desempenho, composição corporal e rendimento de carcaça dos animais, de 22 a 42 dias de idade. As dietas diferiram quanto aos níveis de lisina digestível, mantendo-se a relação dos demais aminoácidos com a lisina.Foram utilizados seis níveis de lisina digestível: 0,88\%; 0,96\%; 1,05\%; 1,13\%; 1,22\%; e 1,30\%. Distribuídos em 36 unidades experimentais de 36 aves cada, 1296 animais da linhagem Cobb - $500^{\circledR}$ tiveram as seguintes características de desempenho avaliadas: consumo de ração (CR), peso corporal (PC), ganho de peso (GP), conversão alimentar (CA), viabilidade criatória (VC) e índice de eficiência produtiva (IEP). Aos 42 dias de idade, foram selecionadas ao acaso cinco aves para avaliação do rendimento de carcaça, e duas para avaliação da composição corporal. A CA, o IEP e o rendimento de peito foram influenciados, sendo sua exigência de 1,30\%, sugerindo que níveis maiores de lisina digestível que as recomendações utilizadas como base neste estudo $(1,13 \%)$ trouxeram benefícios aos animais sobre essas características.

Palavras-chave: aminoácidos, avicultura, rendimento de carcaça, nutrição, proteína ideal

\begin{abstract}
The objective of the present study was to evaluate the optimal levels of digestible lysine in the diet of male broilers, evaluating performance characteristics, body composition, and carcass yield of the animals in the final phase (22 to 42 days old). The diets differed in digestible lysine content, maintaining the relation among the other amino acids and lysine in accordance with the ideal protein concept. The six levels of digestible lysine in the diet were: $0.88 \% ; 0.96 \% ; 1.05 \% ; 1.13 \% ; 1.22 \%$, and $1.30 \%$. A total of 1296 animals were employed, distributed in 36 experimental units of 36 birds each. The determined performance characteristics corresponded to feed intake (FI), body weight (BW), weight gain (WG), feed conversion $(F C)$, viability $(V B)$, and productive efficiency index (PEI). At 42 days of age seven birds per experimental unit were selected at random, five for the estimation of yield and total carcass and commercial cut weight, and two for the evaluation of body composition. FC, animal breast yield and PEI weres influenced with requirements of $1.30 \%$. With respect to nationally known recommendations regarding digestible lysine (1.13\%), higher levels of the amino acid in the diet have brought benefits regarding the characteristics above.
\end{abstract}

Keywords: amino acids, carcass yield, ideal protein, nutritional requirement, poultry

\section{INTRODUÇÃO}

A avicultura brasileira apresentou, nas últimas décadas, avanços extraordinários no que diz respeito à genética, à sanidade, ao manejo e à nutrição, possibilitando-lhe posição de destaque nos agronegócios brasileiro e mundial. Na medida em que a alimentação representa aproximadamente $70 \%$ dos custos totais de produção avícola e possui papel fundamental no desempenho dos animais, estudos objetivando assegurar uma nutrição de baixo custo e, ao

Recebido em 22 de abril de 2019

Aceito em 18 de setembro de 2019

E-mail: vinicius.caetano@usp.br 
mesmo tempo, a melhoria do desempenho animal são de enorme importância para o contínuo desenvolvimento do setor.

Os altos custos com a alimentação das aves estão associados ao atendimento das exigências de proteína e aminoácidos (Nasr; Kheiri, 2012), que são nutrientes caros, visto que, nas dietas formuladas, utilizam-se basicamente milho e farelo de soja como fontes de energia e proteína, respectivamente. Essa combinação de ingredientes resulta em dietas limitantes especialmente em metionina e lisina, sendo necessária a suplementação por meio de aminoácidos industriais, a fim de que as aves tenham suas exigências nutricionais atendidas e expressem ao máximo o seu potencial genético.

Níveis dietéticos de proteína devem servir apenas como base na alimentação da qualidade da dieta de aves e suínos, uma vez que o fornecimento dos aminoácidos essenciais tem maior importância (Rostagno et al., 2011). As necessidades de proteína decompõem-se em exigências por aminoácidos, que são as unidades estruturais primárias formadoras do tecido muscular e de outras proteínas presentes no corpo animal, como penas, pele e enzimas (Fuller; Wang, 1990).

$\mathrm{O}$ atendimento das exigências de aminoácidos para as aves, tomando-se como base o fornecimento de proteína bruta $(\mathrm{PB})$, proporciona rações com níveis de aminoácidos acima das exigências desses animais. A adoção do conceito de proteína ideal na formulação de rações, reduzindo a proteína bruta e suplementando com aminoácidos essenciais, torna o fornecimento de aminoácidos mais ajustado às exigências das aves, possibilitando a elas expressarem seu máximo potencial genético para a produção, além de contribuir para a diminuição da produção de amônia e excreção de nitrogênio, melhorando, assim, o conforto nos galpões (Faria Filho et al., 2006).

A atualização das exigências nutricionais na formulação das rações é necessária e deve ser revista periodicamente, em virtude do contínuo melhoramento genético das aves, visando aumento da produtividade e atendimento das exigências do mercado consumidor. Esse melhoramento genético altera a produtividade e as exigências de mantença dos animais, assim como a velocidade de crescimento, que pode variar com o sexo e a conformação dos frangos (cortes ou carcaças). A lisina se constitui como o aminoácido referência do conceito de proteína ideal; nesse sentido, suas exigências, em todas as fases de criação, devem ser determinadas com muita precisão e clareza, em todos os tipos de manejo e ambiência.

A metodologia empregada neste experimento foi aprovada pelo Comitê de Ética em Pesquisa da FZEA-USP, sob protocolo ${ }^{\circ} .8032260815$.

\section{MATERIAL E MÉTODOS}

Neste ensaio, aprovado pelo Comitê de Ética em Pesquisa da FZEA, protocolado sob o Ceua $n^{\circ}$. 8032260815, 1296 pintinhos machos, de um dia de idade (peso médio 48,5g), da linhagem Cobb$500^{\circledR}$, foram distribuídos em delineamento inteiramente ao acaso (DIC), em 36 unidades experimentais (boxes de $3 \mathrm{~m}^{2}$ ), constituídas por 36 aves cada, divididos em seis tratamentos com seis repetições. O galpão experimental utilizado, de $6 \mathrm{~m} \times 35 \mathrm{~m}$, tem piso de concreto com pé direito de $2,5 \mathrm{~m}$ e é composto por: uma sala central, onde se guardava equipamento e materiais e onde era realizada a pesagem da ração; e duas salas adjacentes, com 20 boxes cada (18 de cada sala foram utilizados). Os pintinhos foram vacinados contra a doença de Marek no incubatório e contra a doença de Newcastle e a de Gumboro, aos sete dias, via ocular.

Para o aquecimento das aves, foram instaladas lâmpadas infravermelhas de $250 \mathrm{~W}$ e campânulas a gás nos corredores, na fase inicial de desenvolvimento. O programa de luz adotado foi de 23 horas de luz + uma hora de escuridão por dia.

Duas vezes ao dia, as máximas e mínimas de temperatura e a umidade relativa do ar (URA) foram registradas, utilizando-se termo-higrômetro marca Hygrotherm ${ }^{\circledR}$ TFA. O cálculo do IEC (índice entalpia de conforto), baseado nas médias de temperatura e URA registradas, foi calculado segundo as tabelas de Queiroz et al. (2012). As médias de temperatura, URA e IEC estão apresentadas na Tab. 1.

No ensaio, os animais foram alimentados com uma dieta-padrão (basal) até 21 dias de idade, seguindo as recomendações de Rostagno et al. (2011). Posteriormente, seis programas de 
alimentação foram fornecidos aos animais até os 42 dias. As aves foram distribuídas entre as parcelas, mantendo-se uma variação de $5 \%$ no peso médio $(794,14 \mathrm{~g})$, sendo as rações formuladas à base de milho e farelo de soja.

As dietas-teste seguiram recomendações de Rostagno et al. (2011) para todos os nutrientes, com exceção da lisina e dos demais aminoácidos (os níveis de aminoácidos seguiram a relação lisina:aminoácido recomendada). Foram seis níveis de lisina digestível testados: $0,88 \% ; 0,96 \%$; $1,05 \% ; 1,13 \% ; 1,22 \%$; e $1,30 \%$, no período de 22 a 42 dias de idade. Esses valores correspondem a $77,5 \% ; \quad 85,0 \% ; \quad 92,5 \% ; 100,0 \% ; 107,5 \%$; e $115,0 \%$ do recomendado por Rostagno et al. (2011) para o período de 22 a 33 dias de idade. Tais níveis foram utilizados para que não houvesse deficiência de aminoácidos na dieta $100,0 \%$ (T4) nos primeiros dias da fase, quando a exigência de aminoácidos é maior.

Tabela 1. Média e desvio-padrão (DP) dos valores de temperatura $\left({ }^{\circ} \mathrm{C}\right)$, de umidade relativa do ar (URA) (\%) e do IEC (índice entalpia de conforto) das aves calculado e de conforto

\begin{tabular}{|c|c|c|c|c|c|c|c|c|}
\hline \multirow{3}{*}{$\begin{array}{l}\text { Período } \\
\text { Índice }\end{array}$} & \multicolumn{4}{|c|}{ Manhã } & \multicolumn{4}{|c|}{ Tarde } \\
\hline & \multicolumn{2}{|c|}{ Temperatura } & \multicolumn{2}{|c|}{ URA } & \multicolumn{2}{|c|}{ Temperatura } & \multicolumn{2}{|c|}{ URA } \\
\hline & Máx. & Mín. & Máx. & Mín. & Máx. & Mín. & Máx. & Mín. \\
\hline Semana 4 & 30,49 & 20,70 & 53,06 & 18,44 & 38,19 & 25,96 & 43,14 & 10,21 \\
\hline DP & 1,66 & 2,05 & 6,09 & 7,64 & 1,43 & 1,76 & 10,17 & 0,39 \\
\hline IEC & Calculado & 38 a 66 & Conforto & 49 a 58 & Calculado & 47 a $79 * *$ & Conforto & 49 a 58 \\
\hline Semana 5 & 30,69 & 21,76 & 67,29 & 33,29 & 35,07 & 24,35 & 63,06 & 29,14 \\
\hline DP & 4,15 & 1,98 & 9,24 & 16,63 & 5,08 & 2,78 & 8,22 & 19,24 \\
\hline IEC & Calculado & 39 a $78 * *$ & Conforto & 40 a 55 & Calculad & 43 a $87 * *$ & Conforto & 40 a 55 \\
\hline Semana 6 & 28.31 & 20.49 & 76.83 & 46.17 & 32.34 & 23.79 & 65.83 & 31.75 \\
\hline DP & 2.39 & 1.94 & 10.18 & 16.02 & 3.52 & 2.76 & 18.64 & 20.95 \\
\hline IEC & Calculado & 37 a $74 * *$ & Conforto & 37 a 52 & Calculado & 43 a $82 * *$ & Conforto & 37 a 52 \\
\hline
\end{tabular}

* IEC na faixa crítica; ** IEC na faixa letal. Demais valores fora da faixa de conforto, situados na faixa de atenção. Fonte: Queiroz et al. (2012).

As dietas foram formuladas pelo método empírico de suplementação, em que a lisina foi suplementada de maneira gradual em uma dieta basal deficiente nesse aminoácido, seguindo recomendações de Sakomura e Rostagno (2007) e D’Mello (2003). Para serem mantidos os níveis nutricionais de EM e PB em todos os tratamentos, foram utilizados farelo de glúten de milho $(60 \%$ PB) e amido de milho.

Os aminoácidos metionina+cistina, treonina, triptofano, arginina e valina foram suplementados em suas formas industriais, atendendo sua relação com a lisina recomendada por Rostagno et al. (2011), em todos os tratamentos. Para assegurar que os níveis dos aminoácidos suplementados fossem incluídos corretamente nas dietas, foram coletadas amostras e determinados os conteúdos de aminoácidos totais e livres pela técnica de cromatografia líquida de alta eficiência (HPLC) (Tab. 2).

As aves foram pesadas no início do período experimental e semanalmente, para determinação do GP e do PC. O CR foi calculado considerandose a diferença entre a quantidade de ração fornecida e as sobras nos comedouros, dividida pelo número de aves corrigido, levando-se em conta o número de aves mortas (Sakomura e Rostagno, 2007). A CA foi calculada pela relação entre o consumo de ração e o ganho de peso das aves. A viabilidade (VB) das aves foi calculada pelo número de aves vivas no início do período menos a mortalidade do período. O IEP foi calculado aos 42 dias de idade, determinado por meio da fórmula: [(ganho de peso diário $(\mathrm{g}) \mathrm{x}$ viabilidade criatória)/(conversão alimentar x 10)]. 
Tabela 2. Composição percentual e valores nutricionais calculados e analisados das dietas experimentais de 22 a 42 dias

\begin{tabular}{|c|c|c|c|c|c|c|}
\hline \multirow{2}{*}{$\begin{array}{l}\text { Item } \\
\text { Ingredientes }\end{array}$} & \multicolumn{6}{|c|}{ Nível de lisina } \\
\hline & 0,877 & 0,961 & 1,046 & 1,131 & 1,216 & 1,301 \\
\hline Milho & 54,49 & 54,49 & 54,49 & 54,49 & 54,49 & 54,49 \\
\hline Farelo de soja & 29,22 & 29,22 & 29,22 & 29,22 & 29,22 & 29,22 \\
\hline Óleo de soja & 4,96 & 4,96 & 4,96 & 4,96 & 4,96 & 4,96 \\
\hline Fosfato bicálcico & 1,33 & 1,33 & 1,33 & 1,33 & 1,33 & 1,33 \\
\hline Calcário calcítico & 0,92 & 0,92 & 0,92 & 0,92 & 0,92 & 0,92 \\
\hline Sal comum & 0,35 & 0,35 & 0,35 & 0,35 & 0,35 & 0,35 \\
\hline Suplemento vitamínico e mineral ${ }^{1}$ & 0,40 & 0,40 & 0,40 & 0,40 & 0,40 & 0,40 \\
\hline Bicarbonato de sódio & 0,15 & 0,15 & 0,15 & 0,15 & 0,15 & 0,15 \\
\hline Cloreto de colina $70 \%$ & 0,03 & 0,03 & 0,03 & 0,03 & 0,03 & 0,03 \\
\hline Antioxidante $^{2}$ & 0,01 & 0,01 & 0,01 & 0,01 & 0,01 & 0,01 \\
\hline Amido de milho & 3,507 & 3,25 & 2,895 & 2,483 & 2,090 & 1,672 \\
\hline Farelo de glúten de milho (60\%) & 3,653 & 3,685 & 3,723 & 3,678 & 3,634 & 3,602 \\
\hline Inerte (areia lavada) & 0,839 & 0,872 & 0,913 & 0,957 & 0,995 & 1,028 \\
\hline L-lisina $\mathrm{HCl} 99 \%$ & 0,018 & 0,128 & 0,237 & 0,347 & 0,456 & 0,566 \\
\hline DL-metionina $99 \%$ & 0,125 & 0,187 & 0,249 & 0,312 & 0,374 & 0,436 \\
\hline L-treonina $98,5 \%$ & - & 0,017 & 0,078 & 0,139 & 0,200 & 0,261 \\
\hline L-arginina Food Grade $98,5 \%$ & - & - & 0,006 & 0,104 & 0,202 & 0,301 \\
\hline L-triptofano $98 \%$ & - & - & - & - & 0,010 & 0,025 \\
\hline L-valina Feed Grade $96,5 \%$ & - & - & 0,042 & 0,124 & 0,182 & 0,252 \\
\hline Total & 100 & 100 & 100 & 100 & 100 & 100 \\
\hline \multicolumn{7}{|l|}{ Composição } \\
\hline $\mathrm{EM}(\mathrm{Mcal} / \mathrm{kg})$ & 3,200 & 3,200 & 3,200 & 3,200 & 3,200 & 3,200 \\
\hline $\mathrm{PB}(\%)$ & 19,80 & 19,80 & 19,80 & 19,80 & 19,80 & 19,80 \\
\hline PB analisada & 20,83 & 19,1 & 20,54 & 20,15 & 20,39 & 20,98 \\
\hline $\mathrm{Ca}(\%)$ & 0,76 & 0,76 & 0,76 & 0,76 & 0,76 & 0,76 \\
\hline P. disponível (\%) & 0,36 & 0,36 & 0,36 & 0,36 & 0,36 & 0,36 \\
\hline $\mathrm{Na}(\%)$ & 0,20 & 0,20 & 0,20 & 0,20 & 0,20 & 0,20 \\
\hline $\mathrm{Cl}(\%)$ & 0,25 & 0,25 & 0,25 & 0,25 & 0,25 & 0,25 \\
\hline $\mathrm{K}(\%)$ & 0,71 & 0,71 & 0,71 & 0,71 & 0,71 & 0,70 \\
\hline Lisina dig. & 0,88 & 0,96 & 1,05 & 1,13 & 1,22 & 1,30 \\
\hline Lys. dig. analisada & 0,93 & 1,01 & 1,10 & 1,14 & 1,25 & 1,27 \\
\hline Treonina dig. & 0,61 & 0,63 & 0,68 & 0,74 & 0,79 & 0,85 \\
\hline Thr. dig. analisada & 0,66 & 0,72 & 0,75 & 0,76 & 0,79 & 0,83 \\
\hline Metionina dig. & 0,37 & 0,43 & 0,49 & 0,55 & 0,61 & 0,67 \\
\hline Meth. dig. analisada & 0,41 & 0,44 & 0,49 & 0,49 & 0,59 & 0,60 \\
\hline Metionina + cistina dig. & 0,63 & 0,69 & 0,75 & 0,81 & 0,88 & 0,94 \\
\hline Meth. + cys. dig. analisada & 0,73 & 0,75 & 0,80 & 0,80 & 0,91 & 0,93 \\
\hline Arginina dig. & 1,13 & 1,13 & 1,13 & 1,22 & 1,31 & 1,40 \\
\hline Arg. dig. analisada & 1,12 & 1,17 & 1,17 & 1,27 & 1,31 & 1,42 \\
\hline Valina dig. & 0,77 & 0,77 & 0,81 & 0,88 & 0,94 & 1,00 \\
\hline Val. dig. analisada & 0,90 & 0,90 & 0,94 & 1,04 & 1,05 & 1,11 \\
\hline Triptofano dig. & 0,20 & 0,20 & 0,20 & 0,20 & 0,21 & 0,22 \\
\hline Trp. dig. analisado & 0,23 & 0,21 & 0,22 & 0,22 & 0,23 & 0,21 \\
\hline
\end{tabular}

${ }^{1}$ Composição do suplemento vitamínico e mineral por kg de produto: vitamina A (mínimo) 1.500.000,00UI/kg; vitamina B1 (mínimo) 350,00mg/kg; vitamina B12 (mínimo) 2.500,00mcg/kg; vitamina B2 (mínimo) 1.000,00mg/kg; vitamina B6 (mínimo) 500,00mg/kg; vitamina D3 (mínimo) 500.000,00UI/kg; vitamina E (mínimo) 2.500,00UI/kg; vitamina K3 (mínimo) 400,00mg/kg; niacina (mínimo) 7.500,00mg/kg; ácido fólico (mínimo) 150,00mg/kg; ácido pantotênico (mínimo) 2.750,00mg/kg; colina (mínimo) 60,40g/kg; cobre (mínimo) 25,00g/kg; ferro (mínimo) $12,50 \mathrm{~g} / \mathrm{kg}$; iodo (mínimo) 300,00mg/kg; manganês (mínimo) 17,50g/kg; selênio (mínimo) 50,00mg/kg; zinco (mínimo) $12,50 \mathrm{~g} / \mathrm{kg}$; virginiamicina $4.125,00 \mathrm{mg} / \mathrm{kg}$; salinomicina $16,50 \mathrm{~g} / \mathrm{kg}$.

${ }^{2}$ Feed Guard ${ }^{\circledR}$ : etoxiquina, BHT, TBHQ, ácido cítrico. 
Aos 42 dias de idade, foram selecionadas sete aves ao acaso por parcela experimental: cinco para avaliação do rendimento e peso de carcaça total e dos cortes comerciais, e duas para avaliação da composição corporal. Após o jejum de alimento de 12 horas para completo esvaziamento do conteúdo do trato gastrointestinal, as aves foram insensibilizadas por eletrochoque, abatidas por sangria, mediante corte da veia jugular, escaldadas, depenadas e evisceradas no Matadouro-Escola da Prefeitura do Campus de Pirassununga (PUSP-FC).

As carcaças evisceradas foram, então, resfriadas por aproximadamente duas horas; após esse período, foram obtidos os cortes comercias de peito sem pele e osso, coxa, sobrecoxa e asa. Em seguida, a carcaça eviscerada e os cortes comerciais foram pesados em balança digital de precisão $(0,01 \mathrm{~g})$.

O rendimento de carcaça foi expresso em peso de carcaça e cortes e em relação ao peso corporal da ave no momento do abate [(peso carcaça $x$ 100/peso vivo)], e o rendimento das partes em função do peso da carcaça eviscerada, sem penas, pés, cabeça e pescoço [(peso da parte x 100/peso carcaça)], conforme Mendes et al.(2004)).

Os animais para análise de composição corporal, após jejum de 12 horas, foram abatidos por choque elétrico, congelados e posteriormente autoclavados e triturados em liquidificador industrial. Foram retiradas amostras representativas do "pool" das aves, que foram secas em estufa de circulação de ar a $65^{\circ} \mathrm{C}$, por 72 horas, moídas em moinho de bola, e submetidas à análise da composição química, seguindo os procedimentos descritos pelo AOAC (Official..., 1996) (teores de proteína bruta, extrato etéreo, matéria seca e cinzas). Os resultados foram expressos em peso do tecido e em relação ao peso corporal da ave no momento do abate [(peso do tecido x 100/peso vivo)].

Os dados foram submetidos à análise de variância, com auxílio do programa estatístico SAS (2004), e, quando houve diferenças significativas, as médias foram comparadas pelo teste de Tukey a $5 \%$ de probabilidade. A estimativa da exigência de lisina digestível foi realizada utilizando-se modelos de regressão linear ou quadrática.

\section{RESULTADOS E DISCUSSÃO}

O CR, o PC, o GP, a CA e a VC no período de 22 a 42 dias encontram-se na Tab. 3.

Tabela 3. Características de desempenho de frangos de corte avaliadas no período de 22 a 42 dias de idade

\begin{tabular}{ccccccc}
\hline $\begin{array}{c}\text { Tratamento/ } \\
\text { Lisina digestível } \\
(\%)\end{array}$ & $\begin{array}{c}\text { CR } \\
(\mathrm{g})\end{array}$ & $\begin{array}{c}\text { PC } \\
(\mathrm{g})\end{array}$ & $\begin{array}{c}\text { GP } \\
(\mathrm{g})\end{array}$ & CA & $\begin{array}{c}\text { VC } \\
(\%)\end{array}$ & IEP \\
\hline $1-0,88$ & 3351 & 2489 & 1686 & 2,000 & 94,20 & 397 \\
$2-0,96$ & 3228 & 2437 & 1652 & 1,949 & 97,14 & 412 \\
$3-1,05$ & 3327 & 2486 & 1696 & 1,966 & 96,43 & 416 \\
$4-1,13$ & 3433 & 2598 & 1797 & 1,917 & 97,06 & 455 \\
$5-1,22$ & 3278 & 2514 & 1713 & 1,920 & 95,29 & 426 \\
$6-1,30$ & 3298 & 2545 & 1754 & 1,880 & 96,57 & 451 \\
CV (\%) & 3,13 & 2,70 & 3,78 & 1,62 & 3,42 & 5,82 \\
Regressão & - & - & - & $\mathrm{L}^{1}$ & - & $\mathrm{L}^{2}$ \\
Exigência & - & - & - & 1,30 & - & 1,30 \\
\hline
\end{tabular}

CR: consumo de ração; PC: peso corporal; GP: ganho de peso; CA: conversão alimentar; VC: viabilidade criatória; IEP: índice de eficiência produtiva.

$\mathrm{L}^{1}$ Efeito linear: $\mathrm{y}=-0,3018 \mathrm{x}+2,2306 \mathrm{R}^{2}=0,87(\mathrm{P}<0,01)$.

$\mathrm{L}^{2}$ Efeito linear: $\mathrm{y}=138,89 \mathrm{x}+292,8 \mathrm{R}^{2}=0,67(\mathrm{P}<0,01)$.

O CR, o PC, o GP e a VC não diferiram $(\mathrm{P}>0,05)$ na fase de 22 a 42 dias de idade. A CA apresentou resposta linear inversamente proporcional aos níveis de lisina digestível, melhorando conforme seu incremento na dieta. Já o IEP apresentou resposta linear positiva em relação aos níveis de lisina digestível. Para essa fase, portanto, os níveis de lisina digestível mais altos foram os mais indicados para melhorar os resultados de CA e IEP dos animais. 
Os resultados dessa fase sugerem que a lisina ou outro(s) aminoácido(s) suplementado(s) foram limitantes ao desempenho dos animais nos níveis mais baixos de lisina. Souza et al. (2016) encontraram piora de $9,7 \%$ na digestibilidade proteica em frangos de corte afetados pelo estresse calórico contínuo (22 a 42 dias). Os animais do presente estudo sofreram com o desconforto causado pelo calor e pela umidade elevados, conforme pode ser verificado na Tab. 2 .

O aumento na temperatura ambiente é conhecido por diminuir o consumo de ração, o ganho de peso e aumentar a conversão alimentar dos animais, especialmente em idades avançadas e, não sendo linear, tende a ser mais severo quanto maior é a temperatura (Daghir, 2008). O metabolismo proteico é afetado pelo menor consumo de nitrogênio, mas, além dos efeitos da diminuição no consumo, o estresse calórico provoca menor síntese proteica e aumento da proteólise, diminuindo a deposição proteica muscular (Temin et al., 2000).

Uma das estratégias empregadas para lidar com o estresse calórico é a utilização de uma dieta com maiores níveis de proteína (e de aminoácidos) para compensar a menor ingestão de alimento pelos animais (Temin et al., 1999), mantendo, assim, um consumo de proteína e aminoácidos suficiente para manter, ou ao menos suavizar, os danos da alta temperatura e umidade ao desempenho animal e à síntese proteica. Rostagno et al. (2017) recomenda um aumento de aproximadamente $1 \%$ na PB e de $0,05 \%$ na lisina digestível para frangos de corte (desempenho regular-médio) após os 21 dias de idade, em situações de estresse calórico de até $31^{\circ} \mathrm{C}$, quando comparados a frangos criados em ambientes com temperaturas e umidades mais controlados.

Goulart et al. (2008) encontraram níveis de lisina digestível para frangos de corte de 22 a 42 dias de $1,00 \%$ e $0,99 \%$ para GP e CA, respectivamente, e resposta linear em CR $(1,15 \%)$, resultados que não corroboram o deste trabalho. Similarmente,
Costa et al. (2001), em trabalho com frangos de corte da linhagem Ross, de 22 a 40 dias de idade, encontraram valores de 1,04 de lisina digestível para CA, porém sem diferenças no CR. Lilly et al. (2011) encontraram melhores valores de CA em animais alimentados com dietas em excesso de lisina $(1,30 \%)$ que nos demais tratamentos $(0,90 \% ; 1,00 \%$; e $1,20 \%)$.

Por outro lado, alguns autores encontraram valores superiores, a exemplo de Viola et al. (2009), que, ao trabalharem com frangos Cobb x Cobb500 de 19 a 40 dias e com níveis de PB de $20,5 \%$, obtiveram resposta linear positiva para PC e GP conforme os níveis de lisina digestíveis aumentaram $(1,22 \%)$, e resposta quadrática de $1,18 \%$ para CA. Esses autores mantiveram os níveis de arginina digestível:lisina digestível, além dos AAs mais utilizados (metionina, metionina+cistina, treonina e triptofano), seguindo o conceito de proteína ideal. Zhai et al. (2016) utilizaram dois níveis de lisina $(1,01 \%$ e $1,22 \%)$ e quatro de metionina em frangos de corte da linhagem Ross 708 entre 22 e 42 dias de idade e encontraram desempenho melhor (GP e CA) dos animais no nível maior de lisina. Além disso, os autores mostraram que, conforme se aumenta a lisina, os resultados de desempenho e carcaça melhoram se o nível de metionina também for maior.

Esses estudos conflitantes demonstram que a exigência de lisina deve ser amplamente estudada na fase final de criação, já que fatores como temperatura, genética, quantidade energética, quantidade proteica e níveis de outros aminoácidos na dieta tendem a alterar significativamente seus valores.

Os resultados de rendimento e peso de carcaça e cortes comerciais, bem como das características de composição corporal em porcentagem e em peso absoluto, no período de 21 a 42 dias de idade, estão apresentados nas Tab. 4, 5, 6 e 7, respectivamente. 
Exigência de lisina...

Tabela 4. Características de rendimento de carcaça e cortes (\%) de frangos de corte aos 42 dias de idade avaliadas no ensaio 2 (22 a 42 dias de idade)

\begin{tabular}{cccccc}
\hline $\begin{array}{c}\text { Tratamento/ } \\
\text { Lisina digestível (\%) }\end{array}$ & Carcaça (\%) & $\begin{array}{c}\text { Peito } \\
(\%)\end{array}$ & $\begin{array}{c}\text { Coxa } \\
(\%)\end{array}$ & $\begin{array}{c}\text { Sobrecoxa } \\
(\%)\end{array}$ & $\begin{array}{c}\text { Asa } \\
(\%)\end{array}$ \\
\hline $1-0,88$ & 80,26 & 23,29 & 9,64 & 13,06 & 7,66 \\
$2-0,96$ & 81,27 & 23,76 & 9,71 & 13,25 & 7,70 \\
$3-1,05$ & 81,25 & 23,78 & 9,61 & 13,11 & 7,68 \\
$4-1,13$ & 80,38 & 24,14 & 9,43 & 12,84 & 7,61 \\
$5-1,22$ & 81,40 & 24,68 & 9,55 & 12,89 & 7,72 \\
$6-1,30$ & 81,15 & 24,80 & 9,66 & 13,25 & 7,53 \\
CV $(\%)$ & 1,09 & 3,33 & 2,81 & 2,26 & 2,03 \\
Regressão & - & $\mathrm{L}^{1}$ & - & - & - \\
Exigência & - & 1,30 & - & - & - \\
\hline
\end{tabular}

$\mathrm{L}^{1}$ Efeito linear: $\mathrm{y}=1,0362 \mathrm{x}^{2}+2,07 \mathrm{x}+21,107 \mathrm{R}^{2}=0,90(\mathrm{P}<0,01)$.

Tabela 5. Características de peso de carcaça e cortes (g) de frangos de corte aos 42 dias de idade avaliadas no ensaio 2 ( 22 a 42 dias de idade)

\begin{tabular}{cccccc}
\hline $\begin{array}{c}\text { Tratamento/ } \\
\text { Lisina digestível }(\%)\end{array}$ & $\begin{array}{c}\text { Carcaça } \\
(\mathrm{g})\end{array}$ & $\begin{array}{c}\text { Peito } \\
(\mathrm{g})\end{array}$ & Coxa $(\mathrm{g})$ & $\begin{array}{c}\text { Sobrecoxa } \\
(\mathrm{g})\end{array}$ & $\begin{array}{c}\text { Asa } \\
(\mathrm{g})\end{array}$ \\
\hline $1-0,88$ & 2209,73 & 644,94 & 266,41 & 362,93 & 211,74 \\
$2-0,96$ & 2227,80 & 653,83 & 266,49 & 363,85 & 211,25 \\
$3-1,05$ & 2223,67 & 657,04 & 264,50 & 361,46 & 211,49 \\
$4-1,13$ & 2266,40 & 683,27 & 266,60 & 363,09 & 214,99 \\
$5-1,22$ & 2292,07 & 693,19 & 267,73 & 360,95 & 216,31 \\
$6-1,30$ & 2310,00 & 708,28 & 275,03 & 377,66 & 214,50 \\
CV $(\%)$ & 4,50 & 6,15 & 4,21 & 5,04 & 4,07 \\
Regressão & ns & ns & ns & ns & ns \\
\hline
\end{tabular}

ns: não significativo.

Tabela 6. Médias das características de composição corporal em porcentagem na matéria original (\%) avaliadas no ensaio 2 ( 22 a 42 dias de idade)

\begin{tabular}{ccccc}
\hline $\begin{array}{c}\text { Tratamento/ } \\
\text { Lisina digestível (\%) }\end{array}$ & $\begin{array}{c}\text { MS } \\
(\%)\end{array}$ & $\begin{array}{c}\text { EE } \\
(\%)\end{array}$ & $\begin{array}{c}\text { MM } \\
(\%)\end{array}$ & $\begin{array}{c}\text { PB } \\
(\%)\end{array}$ \\
\hline $1-0,88$ & 29,74 & 9,19 & 3,01 & 16,15 \\
$2-0,96$ & 28,71 & 9,97 & 2,82 & 15,81 \\
$3-1,05$ & 29,52 & 10,16 & 2,96 & 16,26 \\
$4-1,13$ & 30,58 & 10,87 & 3,08 & 16,45 \\
$5-1,22$ & 29,40 & 10,60 & 3,01 & 15,52 \\
$6-1,30$ & 30,49 & 9,76 & 3,08 & 15,49 \\
CV(\%) & 7,59 & 10,81 & 11,99 & 6,69 \\
Regressão & ns & ns & ns & ns \\
\hline
\end{tabular}

ns: não significativo.

MS: matéria seca; EE: extrato etéreo; MM: matéria mineral; PB: proteína bruta.

Tabela 7. Médias das características de composição corporal em peso calculado (g) avaliadas no ensaio 2 (22 a 42 dias de idade)

\begin{tabular}{ccccc}
$\begin{array}{c}\text { Tratamento/ } \\
\text { Lisina digestível (\%) }\end{array}$ & $\begin{array}{c}\text { MS } \\
(\mathrm{g})\end{array}$ & $\begin{array}{c}\text { EE } \\
(\mathrm{g})\end{array}$ & $\begin{array}{c}\text { MM } \\
(\mathrm{g})\end{array}$ & $\begin{array}{c}\text { PB } \\
(\mathrm{g})\end{array}$ \\
\hline $1-0,88$ & 740,55 & 228,98 & 74,96 & 401,88 \\
$2-0,96$ & 708,71 & 243,15 & 69,71 & 385,80 \\
$3-1,05$ & 735,84 & 253,39 & 73,80 & 406,85 \\
$4-1,13$ & 793,73 & 279,60 & 79,87 & 427,04 \\
$5-1,22$ & 761,24 & 273,82 & 77,76 & 402,02 \\
$6-1,30$ & 776,71 & 248,67 & 78,28 & 394,75 \\
CV(\%) & 7,99 & 12,26 & 11,89 & 7,33 \\
Regressão & $\mathrm{ns}$ & $\mathrm{ns}$ & $\mathrm{ns}$ & $\mathrm{ns}$ \\
\hline
\end{tabular}

ns: não significativo.

MS: matéria seca; EE: extrato etéreo; MM: matéria mineral; PB: proteína bruta. 
Entre as características de carcaça e composição corporal dos animais de 22 a 42 dias de idade, apenas a porcentagem de peito demonstrou diferença significativa, com resposta linear positiva em relação ao nível de lisina, aumentando conforme se elevaram os níveis de lisina digestível na dieta. As demais características não apresentaram respostas significativas $(\mathrm{P}>0,05)$.

Assim como no desempenho, as características de carcaça e composição corporal podem ter sido influenciadas pelas altas temperaturas e pela URA que os animais enfrentaram durante o período. Assim como para CA e IEP, os animais dessa fase apresentaram resposta linear positiva do nível de lisina. O baixo consumo devido ao estresse calórico pode ter afetado os animais dos níveis inferiores de lisina digestível, resultando em consumo abaixo do necessário de aminoácidos e influenciando negativamente sua síntese proteica.

Goulart et al. (2008), em experimento similar, encontraram resposta quadrática para rendimento de peito, com exigência de 1,01 de lisina digestível, nível bem abaixo do encontrado neste trabalho. Os autores também encontraram resposta quadrática para rendimento de coxa e sobrecoxa, de $0,99 \%$ e $1,01 \%$, respectivamente. Viola et al. (2009), em trabalho com frangos de corte de 19 a 40 dias de idade e com nível de PB na dieta de $20,5 \%$, encontraram melhor peso de carcaça, de peito e de coxa com $1,19 \%, 1,15 \%$ e $1,22 \%$ de lisina digestível. Em contrapartida, Dozier et al. (2010) encontraram melhores resultados com níveis inferiores, de 0,981, para frangos de corte Cobb x Cobb700 de 28 a 42 dias de idade para rendimento de peito.

Em estudo com frangos Ross x Ross 308 machos, de 28 a 42 dias de idade, Lilly et al. (2011) encontraram pior rendimento de peito em animais alimentados com dietas contendo níveis baixos de lisina $(0,90 \%)$ do que nos demais tratamentos, resultado similar ao do presente estudo. Os mesmos autores também não encontraram diferenças no rendimento de coxa, porém realizaram a composição por partes (coxa e peito) e encontraram maior deposição de gordura e menor de proteína na coxa dos animais alimentados com dieta deficiente em proteína, mas não encontraram diferenças no peito.

Ghahri et al. (2010) encontraram melhor resposta no maior nível de lisina digestível para peso do peito em frangos de corte de 21 a 42 dias de idade, porém os autores utilizaram nível até $1,10 \%$. Diferentemente do presente estudo, os autores também encontraram resposta para peso de pernas, carcaça e gordura. Similarmente, Bernal et al. (2014) obtiveram resposta linear de lisina digestível em trabalho com frangos de corte machos de 22 a 35 dias de idade, ao trabalharem com maior nível de $1,16 \%$, para rendimento e peso de peito e pernas.

Brito et al. (2016), em trabalho com frangos de corte da linhagem Cobb500 ${ }^{\circledR}$, observaram que, conforme aumentado o nível de lisina na dieta, seguindo o conceito de "proteína ideal”, maior foi a expressão de genes ligados à cadeia de transporte mitocondrial, aumentando a energia mitocondrial e resultando em maior deposição proteica e desempenho dos animais. Esses resultados corroboram os do presente estudo, em que o aumento do nível de lisina na dieta, acima do recomendado por Rostagno et al. (2011), foi favorável ao desempenho dos animais. Além da resposta direta da lisina de promover o desenvolvimento muscular (elevando, assim, a quantidade de PB na carcaça), segundo os autores, dentro do conceito de proteína ideal, também outros aminoácidos, como a leucina, a glicina e a arginina, são fundamentais no processo de síntese proteica, atuando especialmente na expressão de importantes sinalizadores que regulam a síntese proteica (Wu et al., 2014).

Segundo Ghahri et al. (2010), a concentração de lisina na dieta influencia o rendimento de peito e a deposição proteica, entre outros fatores, pela alta concentração de lisina no músculo do peito (Nasr; Kheiri, 2012) e pelo fato de o peito representar uma grande porção da carcaça dos animais. Kidd et al. (1998) já haviam relatado aumento no rendimento de peito ao utilizarem níveis maiores que o recomendado de lisina na dieta de frangos de corte, porém os autores lembram que, apesar desses resultados, o incremento de lisina na dieta pode não ser economicamente justificável devido ao seu custo.

Rostagno et al. (2017) recomendam níveis de lisina digestível $0,11 \%$ (1,24\% comparado com $1,13 \%)$ e $0,01 \%$ ( $1,07 \%$ comparado com $1,06 \%$ ) maiores que os da edição anterior (Rostagno et al., 2011), durante os períodos de 22 a 33 e 34 a 42 dias de idade, respectivamente. Consederando-se esses dados e também os resultados constatados 
neste estudo, pode-se perceber que a exigência desse aminoácido aumentou durante os anos.

\section{CONCLUSÃO}

Os resultados deste trabalho indicam que níveis elevados de lisina digestível $(1,301 \%)$ tendem a trazer benefícios ao desempenho (CA e IEP) e ao rendimento de peito dos animais nas condições deste estudo.

\section{REFERÊNCIAS}

BERNAL, L.E.P.; TAVERNARI, F.C. ROSTAGNO, H.S. ALBINO, LFT. Digestible Lysine Requirements of Broilers. Brazilian Journal of Poultry Science, v.16, n.1, 2014.

BRITO, C.O.; DUTRA, J.L.L.; DIAS, T.N.; BARBOSA, L.T. Effect of dietary lysine on performance and expression of electron transport chain genes in the pectoralis major muscle of broilers. Animal, v.1, p.1-6, 2016.

COSTA, F.G.P.; ROSTAGNO, H.S.; ALBINO, L.F.T. et al. Níveis dietéticos de lisina para frangos de corte de 1 a 21 e 22 a 40 dias de idade. R. Bras. Zootec., v.30, p.1490-497, 2001.

DAGHIR, N,J. Poultry production in hot climates. 2.ed. Wallinford, Oxfordshire: CAB International, 2008. p387.

D'MELLO, J.P.F. Responses of growing poultry to amino acids. In: (Ed.). Amino acids in animal nutrition. 2.ed. New York: CAB International, 2003. p.237-260.

DOZIER, W.A.; CORZO, A.; KIDD, M.T. et al. Digestible lysine requirements of male broilers from 28 to 42 days of age. Poultry Science, v. 89, p.2173-2182, 2010.

FARIA FILHO, D.E.; EMYGDIO, D.; FIGUEIREDO, D.F. et al. Dietas de baixa proteína no desempenho de frangos de corte criados em diferentes temperaturas. Pesqui. Agropecu. Bras., v.41, p.101-106, 2006.

FULLER, M.F.; WANG, T.C. Digestible ideal protein - a meansure of dietary protein value. Pig News Inf., v.11, p.353-357, 1990.

GHAHRI, H.; GAYKANI, R.; TOLOIE, T. Effect of dietary crude protein level on performance and lysine requirements of male broiler chickens. Afr. J. Agric. Res., v.5, p.1228-1234, 2010.
GOULART, C.C.; COSTA, F.G.P.; NETO, R.C.L. et al. Exigência de lisina digestível para frangos de corte machos de 1 a 42 dias de idade. Revista Brasileira de Zootecnia, v.37, n.5, p.876-882, 2008.

KIDD, M.T.; KERR, B.J.; HALPIN, K.M.; MCWARD, G.W.; QUARLES, C.L. Lysine levels in starter and grower-finisher diets affect broiler performance and carcass traits. J. Appl. Poult. Res., v.7, p.351-358, 1998.

LILLY, R.A.; WES, S.; CORZO, A.; JUAN, L.S.; MARTIN, J.M. The effects of dietary amino acid density in broiler feed on carcass characteristics and meat quality. Journal of Applied Poultry Reseach, v. 20, p. 56-67, 2011.

MENDES, A.A.; MOREIRA, J.; OLIVEIRA, E.G.; GARCIA, E.A.; ALMEIDA, M.I.M.; GARCIA, R.G. Efeitos da Energia da Dieta sobre Desempenho, Rendimento de Carcaça e Gordura Abdominal de Frangos de Corte. R. Bras. Zootec., v.33, n.6, p.2300-2307, 2004.

NASR J.; KHEIRI, F. Effects of lysine levels of diets formulated based on total or digestible amino acids on broiler carcass composition. Braz. J. Poult. Sci., v.14, p.233-304, 2012.

OFFICIAL methods of analysis. Washington: AOAC, 1996.

QUEIROZ, M.L.V.; BARBOSA FILHO, J.A.D.; VIEIRA, F.M.C. Guia prático para a utilização de tabelas de entalpia. Fortaleza: Núcleo de Estudos em Ambiência Agrícola e Bem-estar Animal, 2012. Disponível em: <http://www.neambe.ufc.br/index_downloads>. Acessado em: 5 abril 2017.

ROSTAGNO, H.S.; ALBINO, L.F.T.; DONZELE, J.L.; GOMES, P.C. et al. Tabelas brasileiras para aves e suínos: composição de alimentos e exigências nutricionais. 3.ed. Viçosa, MG: UFV, 2011, 252p.

ROSTAGNO, H.S.; ALBINO, L.F.T.; HANNAS, M.I.; DONZELE, J.L. et al. Tabelas brasileiras para aves e suínos: composição de alimentos e exigências nutricionais. 4.ed. Viçosa, MG: UFV, 2017, 488p.

SAKOMURA, N.K.; ROSTAGNO, H.S. Métodos de pesquisa em nutrição de monogástricos. Jaboticabal: FUNEP, 2007. 283p.

SAS user's guide: statistics. Cary: SAS Institute, 2004. (CD ROM). 
SOUZA, L.F.A.; ALVES, P.E.E.; ALMEIDA, R.L.R. et al. How heat stress (continuous or cyclical) interferes with nutrient digestibility, energy and nitrogen balances and performance in broilers. Livest. Sci., v.192, p39-43, 2016.

TEMIM, S.; CHAGNEAU, A.M.; GUILLAUMIN, S. et al. Does excess dietary protein improve growth performance and carcass characteristics in heat-exposed chickens? Poult. Sci., v.78, p.312-317, 2000.

TEMIM, S.; CHAGNEAU, A.M.; GUILLAUMIN, S. et al. Effects of chronic heat exposure and protein intake on growth performance, nitrogen retention and muscle development in broiler chickens. Reprod. Nutr. Dev., v.39, p.145-156, 1999.
VIOLA, T.H.; KESSLER, A.M.; RIBEIRO, A.M.L.; SILVA, I.C.M.; KRÁS, R. The influence of crude protein level in the basal diet on the determination of lysine requirements for broiler performance and part yields. Braz. J. Poult. Sci., v.11, p.155-160, 2009.

WU, G.; BAZER, F.W.; DAI, Z. et al. Amino acid nutrition in animals:protein synthesis and beyond. Ann. Rev. Anim. Biosci., v.2, p.387-417, 2014.

ZHAI, W.; PEEBLES, E.D.; SCHILLING, M.W.; Y. MERCIER, Y. Effects of dietary lysine and methionine supplementation on Ross 708 male broilers from 21 to $42 \mathrm{~d}$ of age (I): growth performance, meat yield, and cost effectiveness. J. Appl. Poult. Res., v.25, p.197-211, 2016. 